\title{
OBSERVATIONS ON THE CAROTID BRUIT
}

\author{
W. B. MATTHEWS
}

From the Derbyshire Royal Infirmary

The reported results of surgical treatment of carotid atheroma indicate that disobliteration of an occluded vessel is relatively safe but unlikely to produce much benefit, whereas operating on a stenosed artery is more hazardous but also more rewarding. This naturally throws great emphasis on the diagnosis of carotid stenosis as opposed to occlusion, a difficult clinical exercise. Patients with slight symptoms, those most likely to benefit, often resist the suggestion that they enter hospital for unpleasant investigations and the physician may well have qualms in recommending that they do so. The natural history of untreated carotid stenosis is unknown and angiography is not without risk. However, there is one physical sign which has been claimed to be of value in distinguishing between stenosis and occlusion, the presence of an arterial bruit. Edwards, Gordon, and Rob (1960) stated that "In the absence of a conducted murmur from the heart, a systolic bruit heard over the artery is reliable evidence of a partial stenosis'. Peart and Rob (1960) further state that this bruit was present in $\mathbf{5 9}$ of 103 cases with proved stenosis and that "In no case of complete internal carotid occlusion was this murmur heard". In my own much smaller experience the relation between the bruit and the arterial disease has been more complex.

This paper is not a statistical study but a description of illustrative cases. No example of internal carotid stenosis producing a bruit will be described as this undeniably occurs and requires no further demonstration. In none of the patients described was there a cardiac murmur, anaemia, or subclavian bruit, all possible causes of confusion. The bruits observed were loud harsh noises not obviously affected by posture of the head or pressure of the stethoscope.

\section{Case Reports}

Case 1 (DRI 28619). - A man of 52 was admitted to hospital in November, 1955, with a two weeks' history of progressive left hemiplegia. His condition deteriorated over the next 10 days and he became mentally confused, had a severe hemiplegia, hemianopia, and marked sensory loss. The progressive course suggested a cerebral tumour but a ventriculogram (Mr. G. Clark-Maxwell) was normal. He gradually improved but was left with a residual hemiparesis. In 1957 he developed focal fits in the left upper limb. A bruit was heard over the right carotid. Fig. 1 shows that this was loudest high in the neck, and Fig. 2 that it was entirely systolic, the second heart sound being visible in the tracing at the end of the bruit. Carotid angiography (Fig. 3) showed occlusion of the right internal carotid. The external carotid, although not tightly stenosed, is obviously narrowed at its origin. The bruit persists although it has become softer. The left carotid was not investigated.

Case 2 (DRI 217368). - In January, 1960, this man of 51 sustained a left hemiplegia from which he recovered in the course of a month. In May, 1960, the right upper limb became weak and he was admitted to hospital. He was dysarthric, slightly demented, and the right upper limb was weak. A bruit was heard over both carotids and that on the right is illustrated in Figs. 4 and 5. It was maximal high in the neck and was entirely systolic. Angiography showed stenosis of the left common, and of the internal and external carotid arteries. On the right (Fig. 6) the internal carotid was occluded with stenosis of the external.

Case 3 (DRI 74885). - This man of 54 was first seen in September, 1959, after an episode of slight dysgraphia from which he had recovered. He had slight weakness of the right side of the face and a loud bruit over the left carotid. He refused admission to hospital. In March, 1960, he sustained a left hemiplegia but recovered rapidly and soon afterwards was admitted. The bruit on the left was still present and showed the same characteristics as in the other two patients (Figs. 7 and 8). Angiography showed occlusion of the left internal carotid and probably some narrowing of the external (Fig. 9). On the right good filling of the common and external carotids was obtained but no dye entered the internal carotid. Some dye entered the carotid sheath and as this sometimes produces artefacts it could not be concluded with certainty that the internal carotid was occluded on this side also. Following angiography the patient again developed a left hemiparesis but has now recovered and is at work. 

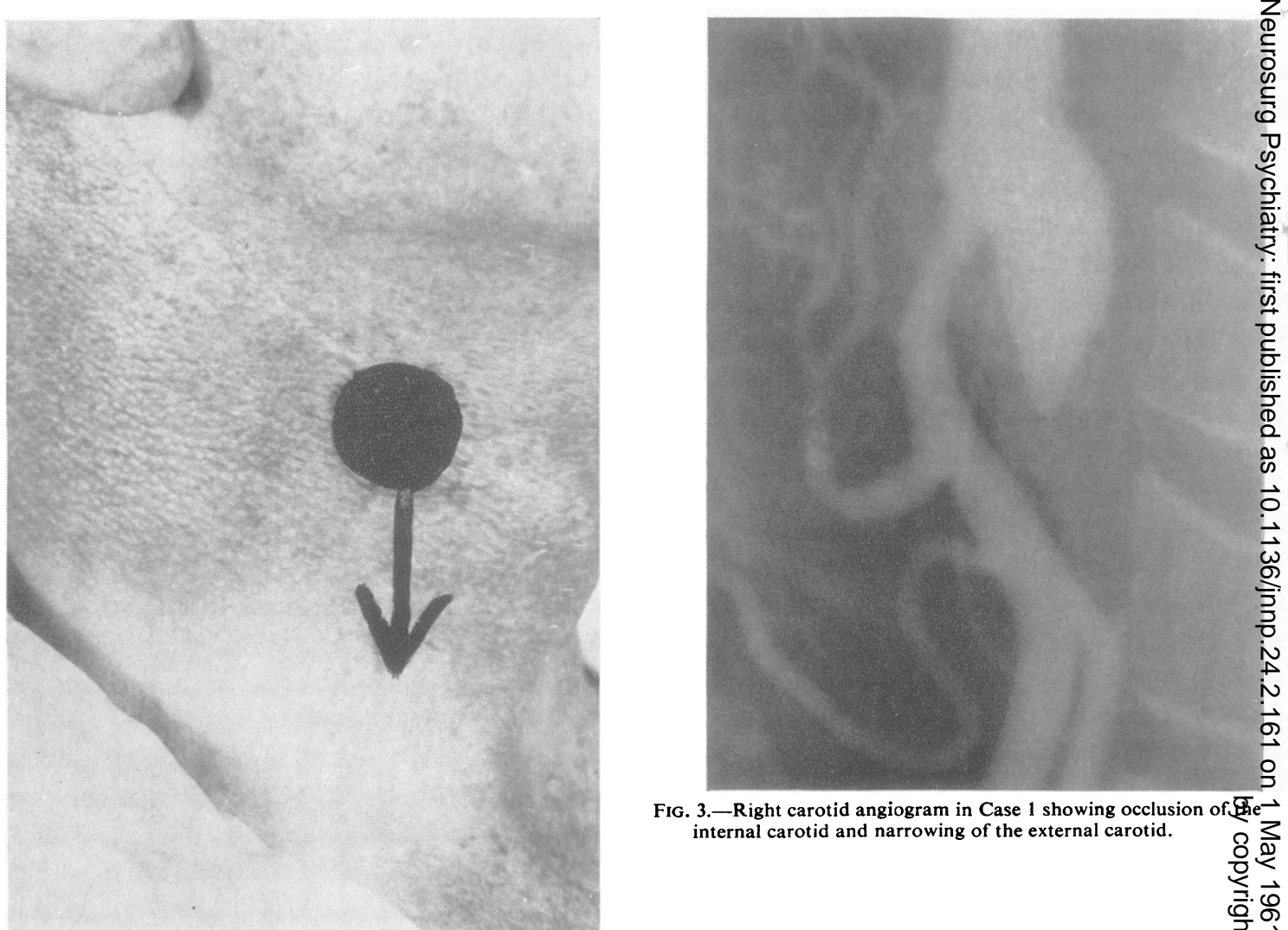

FIG. 3.-Right carotid angiogram in Case 1 showing occlusion of internal carotid and narrowing of the external carotid.

Fig. 1.- Site of bruit in Case 1. In this and subsequent figures the circle marks the point at which the bruit was loudest and from which it was recorded. The arrow marks the approximate area in which it was clearly audible.

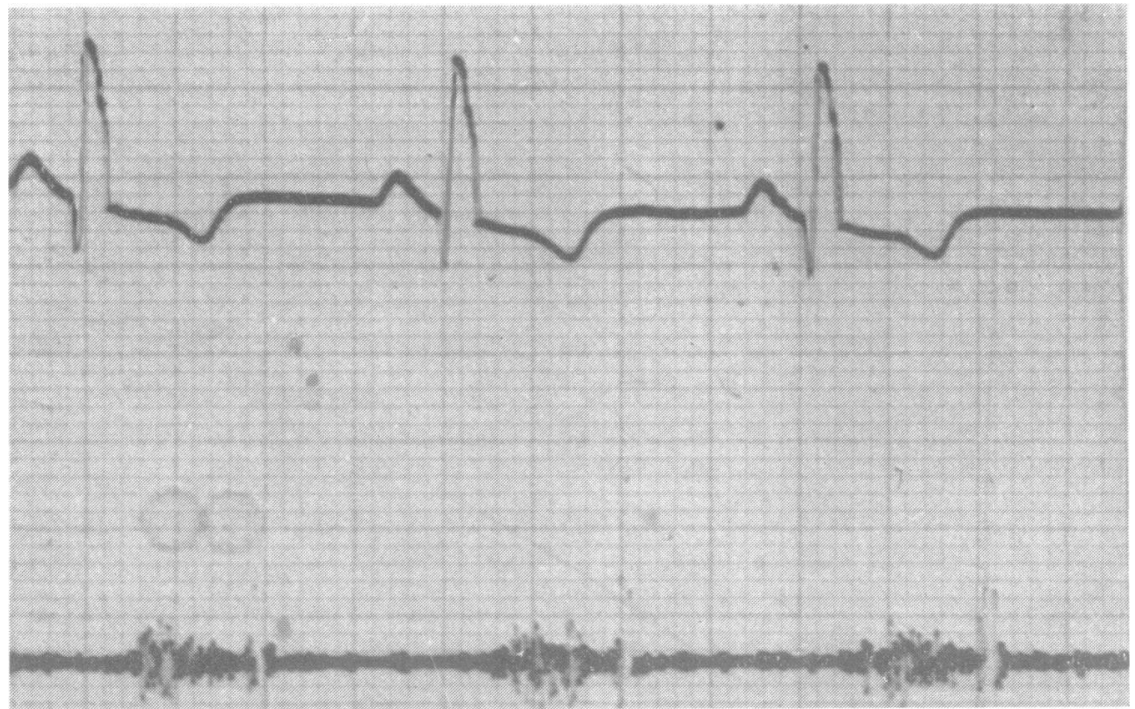

FIG. 2.-Phonocardiogram of the bruit in Case 1. The E.C.G. and carotid bruit are recorded simultaneously. The second heart sound is visible at the end of the bruit. 

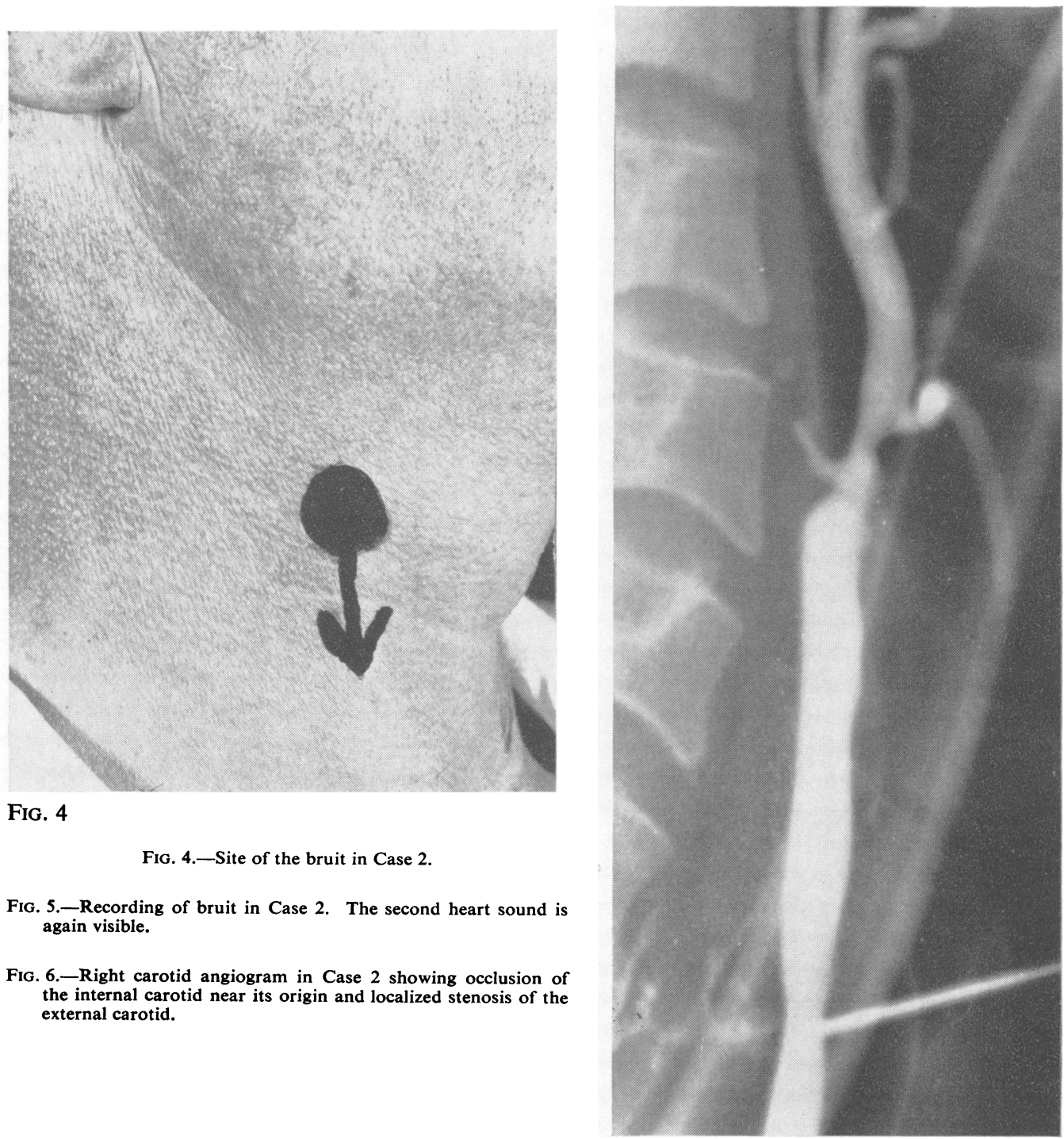

Fig. 4.-Site of the bruit in Case 2.

FIG. 5.-Recording of bruit in Case 2. The second heart sound is again visible.

FIG. 6.-Right carotid angiogram in Case 2 showing occlusion of the internal carotid near its origin and localized stenosis of the external carotid.

FIG. 5

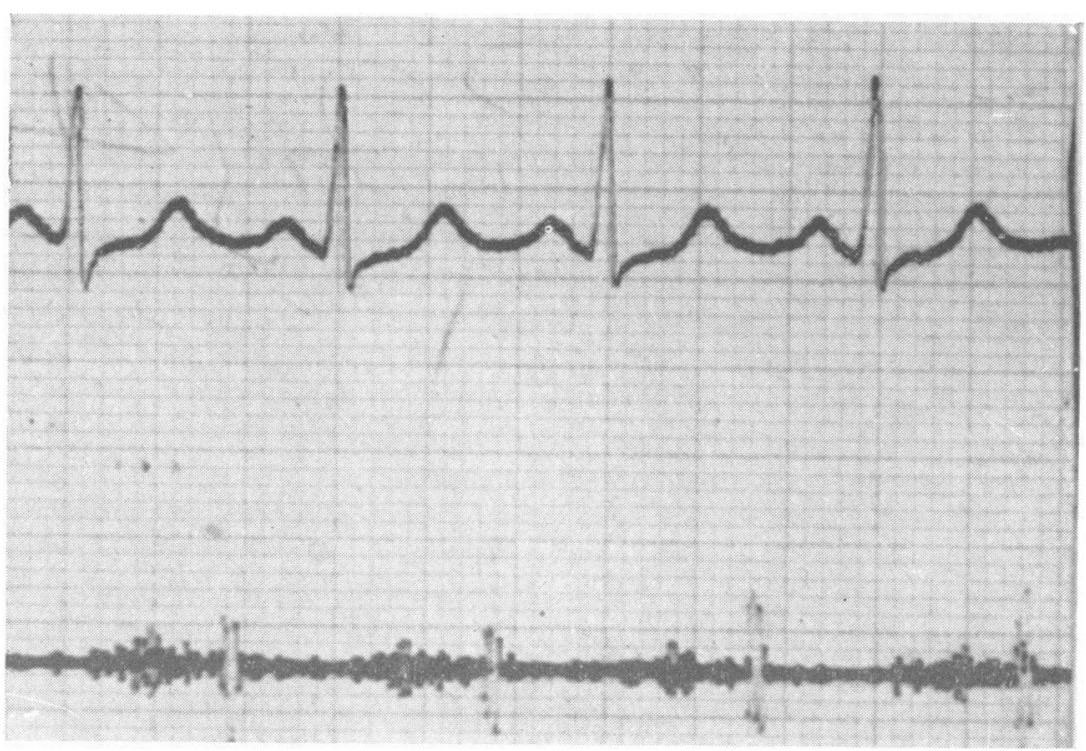

FIG. 6 


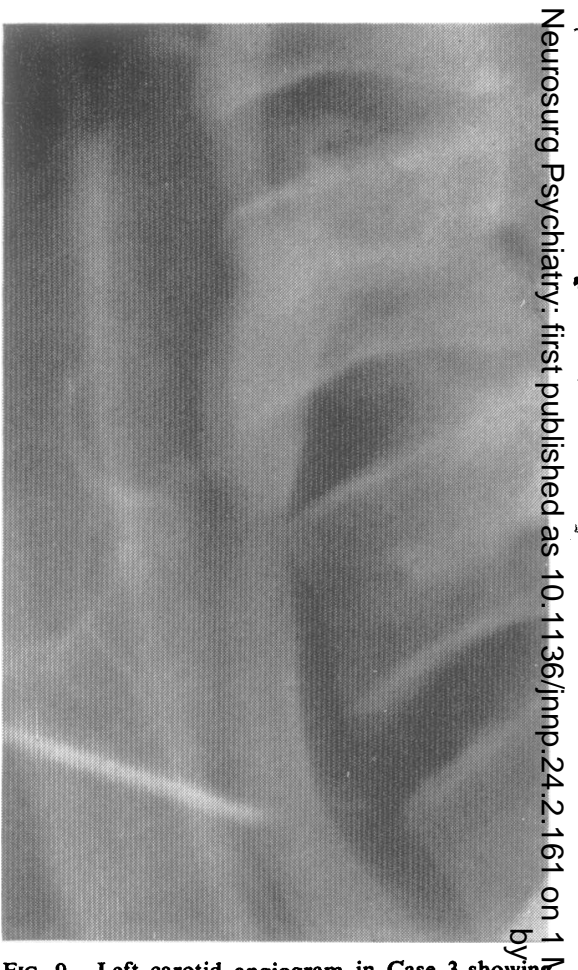

Fig. 9.-Left carotid angiogram in Case 3 showin occlusion of the internal carotid and appareen relative narrowing of the first centimetre one external carotid.

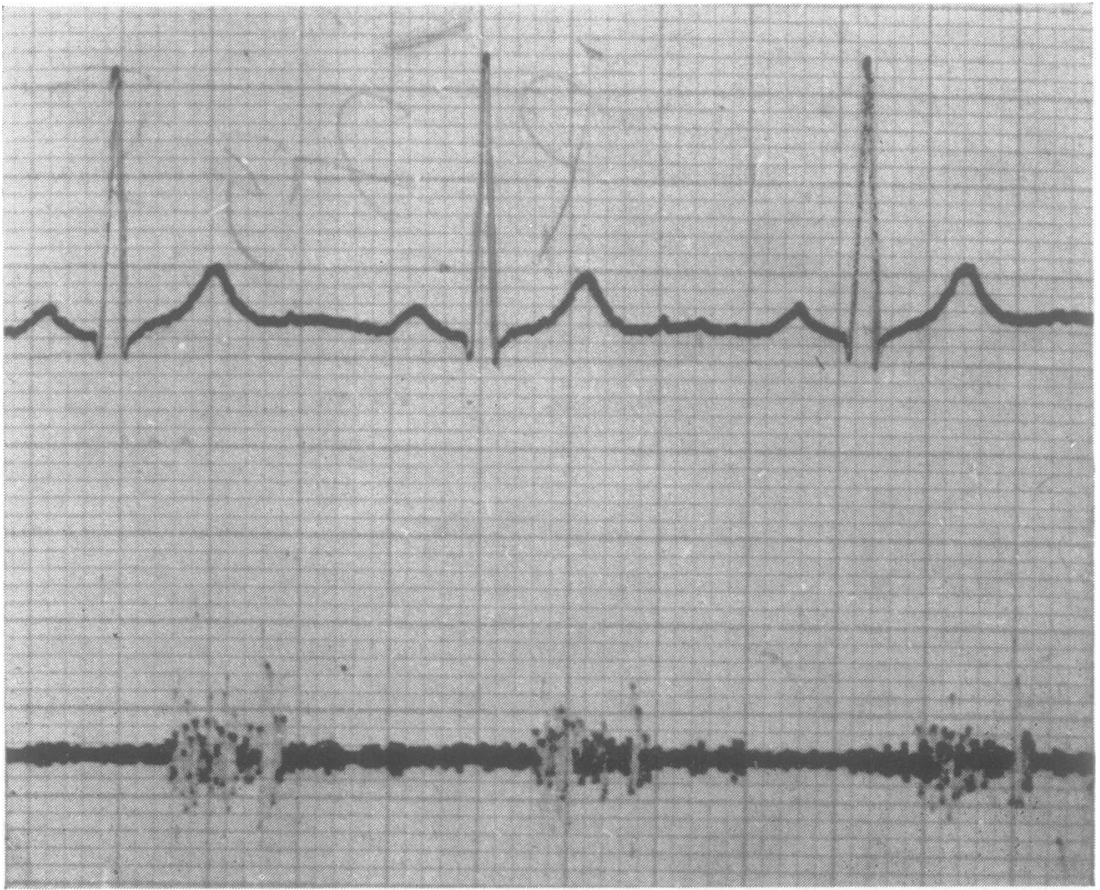




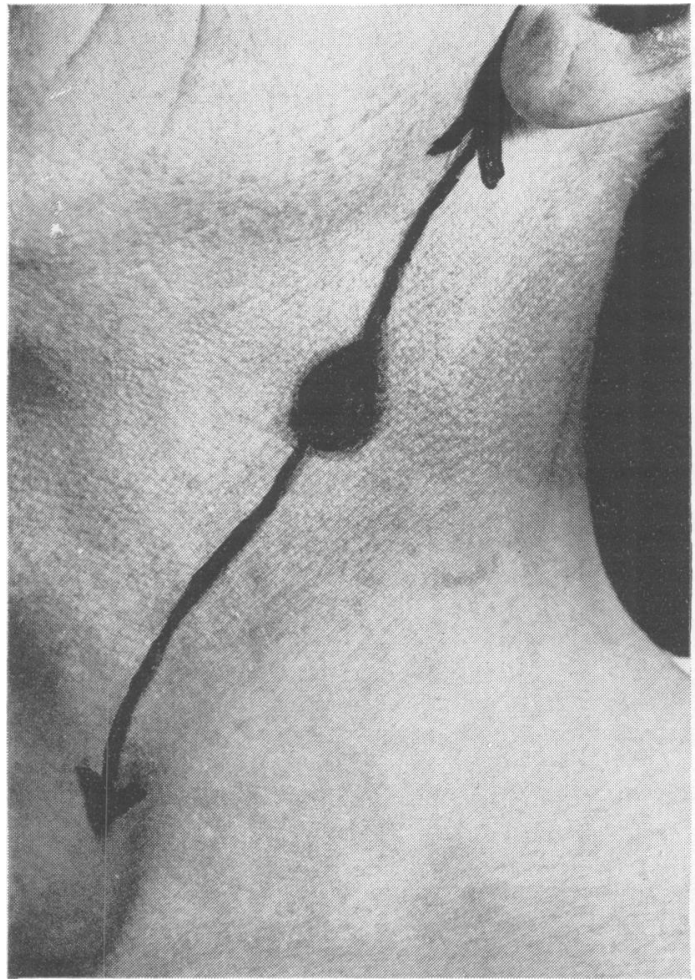

FIG. 10.-Site of bruit in Case 4.

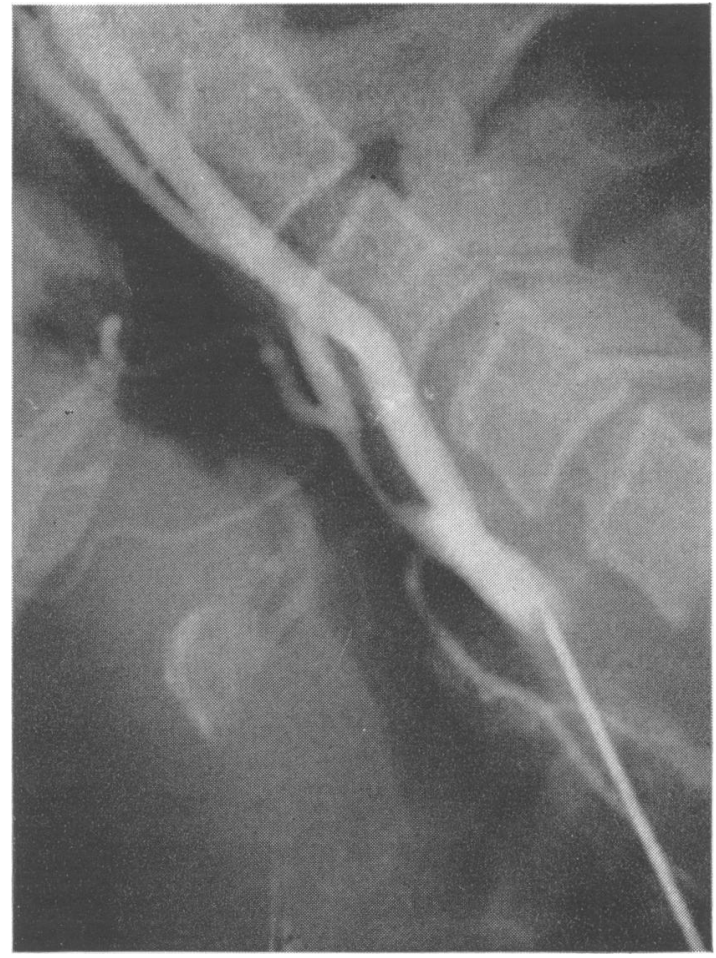

FIG. 12.-Left carotid angiogram in Case 4 showing gross stenosis of the external carotid and a normal internal carotid.

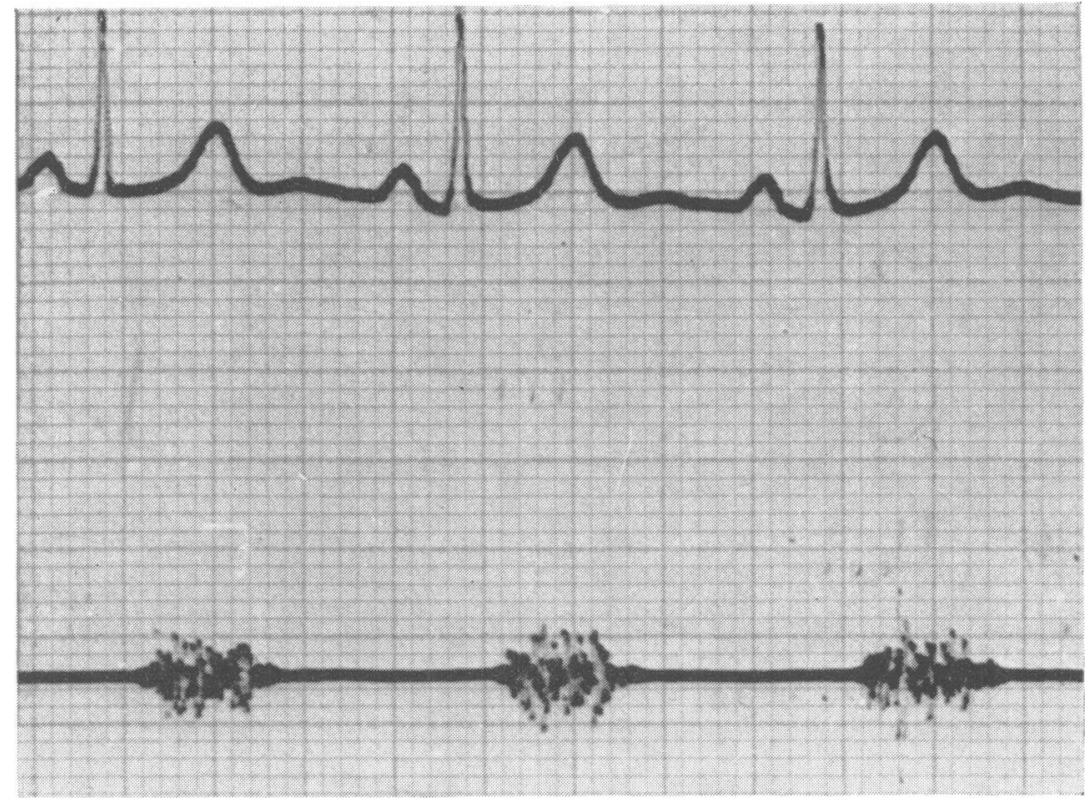

ס 
Case 4 (DRI 212716).-A man of 51, admitted to hospital in November, 1959, gave a complicated history in which he described two distinct types of transitory attack. In one type he would develop weakness of the right lower limb, and in the other, loss of the lower half of the visual field in the right eye. On one occasion he had lapsed into unconsciousness. In quiet surroundings he was aware of a pulsating, roaring noise in his left ear. A loud bruit was audible over the left carotid (Figs. 10 and 11). The patient asked if he might listen to this through a stethoscope and then stated that this was the noise he could hear himself without artificial aids. He was transferred to the care of Dr. Ian Mackenzie at Guy's Hospital, London, where angiography was carried out. This showed stenosis of the right internal carotid and of the external carotid on the left, the side of the bruit (Fig. 12). After an operation for disobliteration of the right internal carotid artery the patient became free from symptoms, but there is now a bruit on the right.

\section{Discussion}

The first three patients demonstrate that a bruit may be present over a completely occluded internal carotid artery, the external carotid being narrowed to varying degrees. These murmurs completely fulfilled the criteria laid down by Peart and Rob (1960) as being characteristic of internal carotid stenosis, loudest in the region of the bifurcation of the artery and confined to systole. These authors mention one patient with a similar bruit associated with stenosis of the external carotid alone, and this is illustrated by my fourth patient in whom the bruit was on the side of the external stenosis, the stenosis of the internal carotid on the other side being silent.

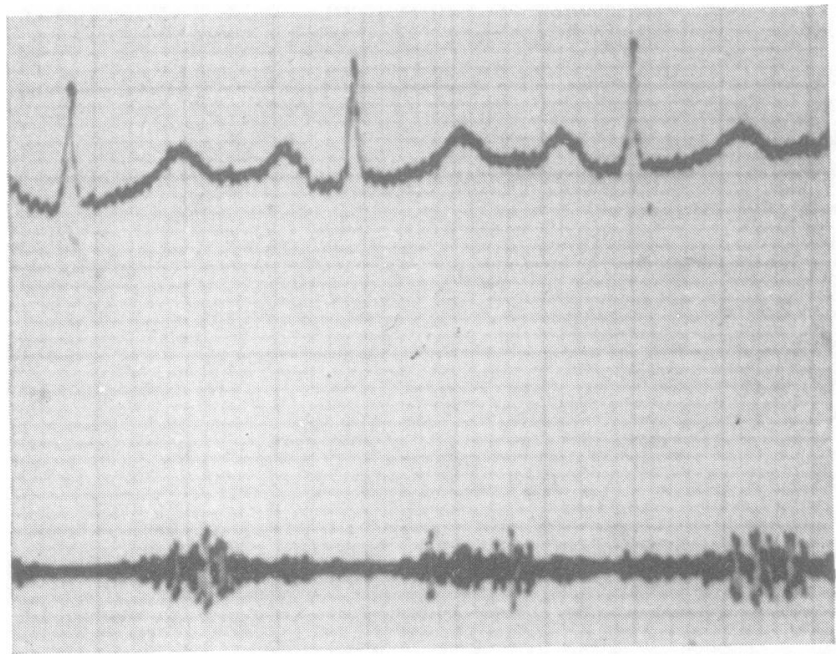

FIG. 13.-Recording of bruit in Case 5. Some respiratory noise is also recorded and the second heart sound is not visible but the timing of the bruit does not appear to differ from that in the preceding cases.
I am, however, doubtful whether arterial stenosis is the sole cause of bruits in arterial disease. Theo possible role of increased blood flow through? collateral vessels is illustrated by the followingo case.

Case 5 (DRI 218609).-A woman of 36 was admitteco with a subarachnoid haemorrhage. No bruit was audibler. over the skull or carotids. Bilateral carotid angiography showed a small carotid aneurysm on the right. The com? mon carotid on that side was ligated (Mr. R. HO Shephard) but doubts were cast on the full efficacy of this by the immediate appearance of a bruit over thes ligature. At a second operation to ligate the interna政. carotid it was found that the original ligature had pero mitted some blood flow although the temporal pulse had been absent. After the second operation no bruit was audible over either carotid. Seven days later, however; a bruit became audible over the left carotid (Fig. 13) and has persisted for six months.

This bruit was not distinguishable in any way fron? those observed in the patients with arterial disease in the neck. Atheroma cannot, of course, be entirely excluded as a cause in this patient but must be regarded as extremeiv ly unlikely and I suggest that increased blood flow in the normal vessel is a more probable cause. Further observations on patients with carotid ligations are in progress?

From these examples it must be concluded tha there is no simple relationship between stenosisoof the internal carotid artery and a systolic arteñia bruit. I believe that such a bruit may be important evidence of atheroma of the vessels in the neck but that angiography is regrettably necessary for the accurate diagnosis of occlusive caroti artery disease.

\section{Summary}

Three patients are described with carotid bruit on the same side as a conf pletely occluded internal carotid artery and one patient with a bruit over a stenoseğ external carotid and an apparently norma internal carotid. The possible roles of external carotid stenosis and of increaseg blood flow in collateral vessels are diş cussed.

I wish to acknowledge with thanks Dr. R D. Hoare's permission to reproduce the angio: gram in Case 4 and Mr. R. H. Shephardis permission to describe Case 5 .

\section{REFERENCES}

Edwards, C. H., Gordon, N. S., and Rob, C. (196]. Quart. J. Med., 29, 67.

Peart, W. S., and Rob, C. (1960). Lancet, 2, 219. 